\title{
Stentless aortic reoperation: New surgical strategy with rapid deployment valves
}

\author{
Gian Luca Martinelli, MD, ${ }^{a}$ Attilio Cotroneo, MD, ${ }^{\mathrm{b}}$ Pierpaolo Greco, MD, ${ }^{\mathrm{b}}$ and Mauro Cassese, MD, \\ Roma, Monza, and Bari, Italy
}

Repeat aortic valve replacement (rAVR) is associated with increased risk due to advanced patient age and comorbidities. Recent guidelines ${ }^{1,2}$ recommend reoperation both in patients with symptoms with significant increases in transprosthetic gradient or severe regurgitation (class I, level of evidence C) and in patients without symptoms with significant prosthetic dysfunction and low-risk for reoperation (class IIa, level of evidence C). ${ }^{1}$

Reoperations $^{3,4}$ as a result of failed stentless valves represent a special group of patients who carry additional procedural challenges. Today, in addition to traditional techniques, we have 2 new surgical options: interventional valve-in-valve techniques and rapid-deployment valves (RDVs) or sutureless valves.

The Edwards INTUITY Elite RDV system (Edwards Lifesciences, Irvine, Calif) has been used successfully for reoperation to treat a failed stentless bioprosthetic valve. ${ }^{5}$ Both cases reported here were not suitable for valve-invalve procedures because of the presence of ascending aortic aneurysm and acute endocarditis.

\section{CLINICAL SUMMARIES \\ Case 1}

The first case was that of a 69 -year-old man with a history of aortic valve replacements (1996-2000). The root and mechanical prosthesis were replaced in 2000 because of endocarditis complicated by a periaortic abscess with a stentless Medtronic Freestyle 25-mm valve (Medtronic, Inc, Minneapolis, Minn), which was implanted as a partial aortic root to exclude the neoabscess cavity at the level of the noncoronary Valsalva sinus after reconstruction of the aortoventricular continuity. In 2014, the patient was

From the ${ }^{\mathrm{a} D e p a r t m e n t}$ of Cardiac Surgery, Campus Universitario Bio-Medico, Roma, Italy; the ${ }^{\mathrm{b}}$ Department of Cardiac Surgery, Policlinico di Monza, Monza, Italy; and the ${ }^{\mathrm{c}}$ Department of Cardiovascular Surgery, Casa di Cura Santa Maria, Bari, Italy.

Disclosures: G.L.M. and M.C. report speaker and consulting fees from Edwards Lifesciences. The other authors have nothing additional to disclose with regard to commercial support.

Received for publication Jan 20, 2015; revisions received March 7, 2015; accepted for publication March 21, 2015; available ahead of print April 22, 2015.

Address for reprints: Gian Luca Martinelli, MD, Department of Cardiac Surgery, Campus, Universitario Bio-Medico, Via Alvaro del Portillo 200, Roma, Italy

(E-mail: martinelligluca@gmail.com).

J Thorac Cardiovasc Surg 2015;149:e88-9

$0022-5223 / \$ 36.00$

Copyright (c) 2015 by The American Association for Thoracic Surgery

http://dx.doi.org/10.1016/j.jtcvs.2015.03.043

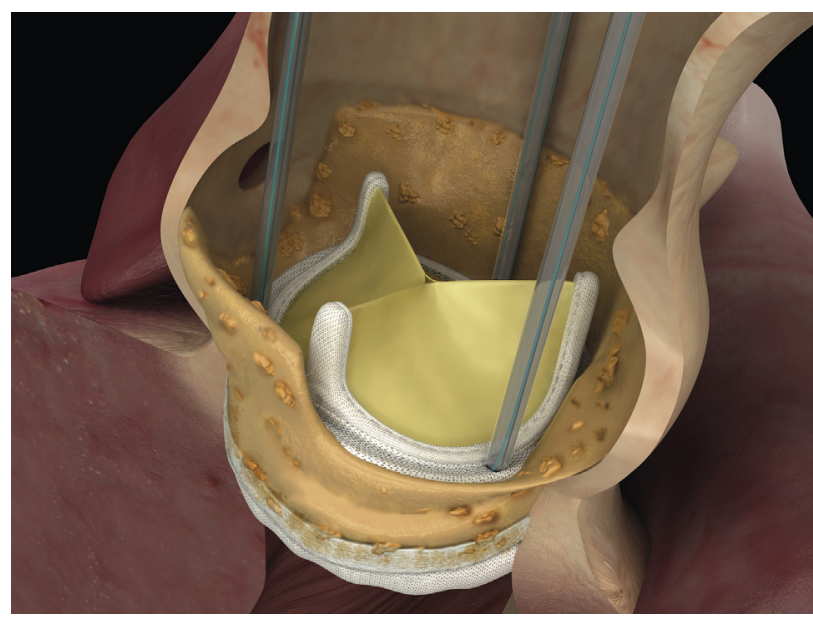

FIGURE 1. The Edwards INTUITY Elite valve is positioned at the level of the native aortic annulus inside the failed stentless valve. Three guiding sutures are passed at the level of the nadir of the 3 cusps from the stentless valve and to the aortic wall.

seen with symptoms of heart failure (New York Heart Association functional class III), a logistic euroSCORE of 13.2, and chronic renal insufficiency. Transthoracic echocardiography (TTE) showed complete calcification of the aortic root with massive aortic regurgitation as the result of an eversion of 1 cusp and ascending aortic aneurysm. The patient underwent rAVR, during which all leaflets were removed and an extremely calcified aortic root was confirmed. An Edwards INTUITY Elite 23-mm valve was implanted inside the aortic root $(25-\mathrm{mm}$ Freestyle has an internal diameter of $22 \mathrm{~mm}$ ), and ascending aortic replacement was performed. Early postoperative TTE showed a well-functioning aortic prosthesis, no paravalvular leaks (PVLs), an ejection fraction of $48 \%$, peak pressure gradient (PPG) of $16 \mathrm{~mm} \mathrm{Hg}$, and mean pressure gradient (MPG) of $8 \mathrm{~mm} \mathrm{Hg}$. He was discharged on day 15 to a rehabilitation clinic. At 6 months of follow-up, the patient was in New York Heart Association class II, TTE showed no PVLs, the ejection fraction was $52 \%$, and MPG was $6 \mathrm{~mm} \mathrm{Hg}$.

\section{Case 2}

The second case was that of an 84-year-old woman with a history of AVRs (2002-2008) with stentless Elan prostheses (Vascutek Ltd, a Terumo Company, Inchinnan, UK) implanted 
as a subcoronary bioprosthesis. The patient was transferred from another hospital with fever and symptoms of heart failure as a result of prosthetic valve endocarditis and severe aortic regurgitation. TTE showed vegetation $(0.7 \times 0.3 \mathrm{~cm})$ of 1 leaflet, resulting in severe incompetence, and her blood cultures were positive for Staphylococcus warneri. Because of persistence of heart failure, surgery was performed before completion of the antibiotic course. All leaflets were removed, and an Edwards INTUITY Elite 19-mm valve was implanted inside the stentless graft. At 6 months of follow-up, she was in good general health with no sign of residual infection; TTE showed a well-functioning aortic prosthesis, no PVLs, an ejection fraction of $50 \%$, peak pressure gradient of $10 \mathrm{~mm} \mathrm{Hg}$, and MPG of $6 \mathrm{~mm} \mathrm{Hg}$.

\section{DISCUSSION}

Reoperation after stentless AVR is challenging and frequently requires aortic root replacement. The University of Toronto reported an incidence of $63 \%$ for the Bentall procedure in rAVR as a result of severe adhesions between the stentless valve and the native aortic root. ${ }^{3}$ In case 1 , we observed extreme calcification of the entire Freestyle bioprosthesis and native aortic root. After considering the Bentall procedure, we used the RDV, which allowed us to fix the prosthesis quickly and easily in the left ventricular outflow tract by the frame stent with only 3 guiding sutures at the nadir of each sinus (Figure 1).

The 23-mm Elite also showed excellent hemodynamic performance at follow-up, with MPG of $6 \mathrm{~mm} \mathrm{Hg}$ and no PVLs. In case 2 , the infection was limited in one cusp. After resection of the leaflets, the remaining annulus of the bioprosthesis and the native aortic root were completely blended, and the left main coronary was attached to the annulus.

The internal diameter was $19 \mathrm{~mm}$. The RDV system enabled positioning of the prosthesis with no risk of coronary occlusion, because the guiding suture placed in the nadir of the left coronary sinus ensured correct intraannular positioning of the prosthesis.

Although further investigations are needed, this more conservative surgical technique with RDV introduction inside the stentless graft represents a new additional treatment option for patients requiring rAVR, making the operation easier and potentially less dangerous. Furthermore, it is associated with excellent hemodynamic performance.

\section{References}

1. Joint Task Force on the Management of Valvular Heart Disease of the European Society of Cardiology (ESC); European Association for Cardio-Thoracic Surgery (EACTS); Vahanian A, Alfieri O, Andreotti F, Antunes MJ, Baròn-Esquivias G, Baumgartner H, et al. Guidelines on the management of valvular heart disease (version 2012). Eur Heart J. 2012;33:2451-96.

2. Nishimura RA, Otto CM, Bonow RO, Carabello BA, Erwin JP III, Guyton RA, et al ACC/AHA Task Force Members. 2014 AHA/ACC guideline for the management of patients with valvular heart disease: executive summary: a report of the American College of Cardiology/American Heart Association Task Force on Practice Guidelines. Circulation. 2014;129:2440-92. Erratum in: Circulation. 2014;129:e650.

3. Borger MA, Prasongsukarn K, Armstrong S, Feindel CM, David TE. Stentless aortic valve reoperations: a surgical challenge. Ann Thorac Surg. 2007;84: 737-43; discussion 743-4.

4. Finch J, Roussin I, Pepper J. Failing stentless aortic valves: redo aortic root replacement or valve in a valve? Eur J Cardiothorac Surg. 2013;43:495-504.

5. Gariboldi V, Grisoli D, Devin A, Nee L, Theron A, Hubert S, et al. Reoperation for failure of freestyle bioprosthesis using an Edwards Intuity valve. Ann Thorac Surg. 2013;96:e47-8.

\title{
Cryptic recurrent mitral valve excrescences: A rare cause of stroke
}

\author{
David Rose, MD, ${ }^{a}$ Andrew Knowles, MD, ${ }^{a}$ Mark Sissons, MD, ${ }^{b}$ and Joseph Zacharias, FRCS (CTh), \\ Blackpool, United Kingdom
}

\footnotetext{
From the ${ }^{a}$ Lancashire Cardiac Centre, Blackpool, United Kingdom; and the ${ }^{\mathrm{b}}$ Department of Pathology, Blackpool Victoria Hospital, Blackpool, United Kingdom.

Disclosures: J.Z. is a proctor for Edwards Lifesciences and is reimbursed for the time spent proctoring. All other authors have nothing to disclose with regard to commercial support.

Received for publication Jan 24, 2015; revisions received March 1, 2015; accepted for publication March 26, 2015; available ahead of print April 22, 2015.

Address for reprints: David Rose, MD, Lancashire Cardiac Centre, Whinney Heys Rd, Blackpool, Lancashire FY3 8NR, United Kingdom (E-mail: davidrose@ libero.it).

J Thorac Cardiovasc Surg 2015;149:e89-91

$0022-5223 / \$ 36.00$

Copyright (c) 2015 by The American Association for Thoracic Surgery

http://dx.doi.org/10.1016/j.jtcvs.2015.03.043
}

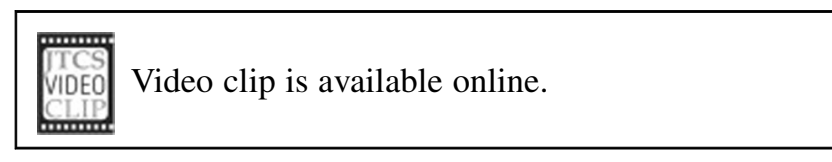

Mesothelial monocytic intracardiac excrescence is considered a benign cardiovascular lesion, but because of its very particular morphology and considering its recurrent behavior, we suggest for this rare valve lesion a strategy to replace the valve rather than attempting a repair. 